\title{
E-Commerce Strategy Assessment
}

\author{
Asmahan Majed Altaher \\ Applied Sciences University, Amman, Jordan
}

\begin{abstract}
Strategy assessment is the continuous evaluation of the organizations strategic goals, resulting in correctives action and if necessary strategy reformulation. The firms need to specific measures called metrics to assist the progress of the strategy and evaluate the performance improvement initiatives; one of the most popular metrics is balanced scorecard. This paper investigates how to use the BSC metrics to measure the bank's strategy. The aims of the study are to identify the effects of implementing balanced scorecard metrics for e-commerce strategy assessment. The researcher investigates the relation between balanced scorecard metric and the e-commerce strategy in Jordan e-banking. The study will be drawn upon qualified questionnaires which have been sent to strategic management at Jordanian banks to collect the needed data and to test the research hypotheses. The results recommend that managers should align strategy performance by measuring what drives success, and prioritize e-initiatives based on accurate metrics. Strategic managers should be a wear for customer needs and requirements, banks need to maintain their customer services in which customers have easy access to information for banks services.
\end{abstract}

Keywords: strategy assessment, balance scorecard, finances metric, internal processes, customization and customer's interaction

\section{Introduction}

Strategy assessment is the continuous evaluation of the organizations strategic goals, resulting in correctives action and, if necessary, strategy reformulation. Organizations, therefore, should respond to changeable environment by redesigning internal and external processes. (Maiga \& Jacobe, 2003) argued that balanced scorecard (BSC) has been considered as a main tool in evaluating organization strategy, and evaluating the performance improvement initiatives. BSC is a popular strategy, and assessment methodology that encourages measuring organizational performance in a number of areas related to finance, human resources, internal processes, and customers (Turban, King, Lee, \& Viehland, 2008).

Balanced scorecard is road maps for executing strategy and to determine a measure for scoring and evaluating the organization strategy (Turban et al., 2008). Numbers of authors have looked for the topic and introduce a metric. Plant (2000) suggested seven areas for assessment of an e-commerce strategy: financial, impact, competitive, brand, service, market, technology, and internal site metric. Jaworski (2004) proposed five categories of financial and non-financial metrics. Similarly, Zhu, and Kraemer (2002) defined four metrics in informational areas, these metrics were: finance impact, internal process, customers' interaction, and customization. In this study the authors adapted (similarly et al., 2002) matrices to investigate the effect in the

Asmahan Majed Altaher, Ph.D., Assistant Professor, Department of Management Information System, Applied Sciences University.

Correspondence concerning this article should be addressed to Asmahan Majed Altaher, Po. Box 166 Amman 11391 Jordan. E-mail: a_altaher68@hotmail.com. 
strategy assessment in Jordan e-banks. This paper investigates the variables that underlie BSC, and how are they used to measure banks strategy.

The paper also describes and illustrates BSC as a key metrics required for the success of the strategy assessment. In the following section, of the study: research model and hypotheses, literature review, research design and methodology, result, and conclusion.

\section{Research Model}

The research model Figure 1 depends on fours metrics choices from Similary, Zhu, and Kraemer (2002). They suggest four metrics areas - informational, financial impact, internal process, customization and interaction with customer. The researchers adapt the previous matrices and develop questionnaire to investigate the relation between balanced scorecard metric and the e-banks strategy assessment.

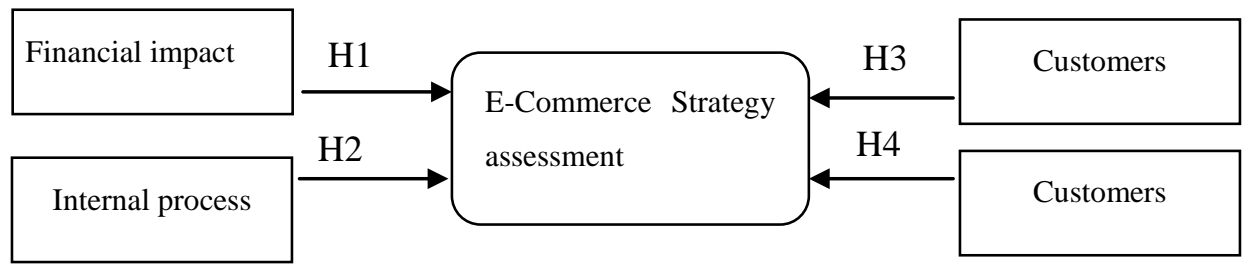

Figure 1. Research model. Source: Researcher.

\section{Hypotheses}

H1: There is a significant positive effect between balanced scorecard metric and the e-banks strategy assessment.

H2: There is a significant positive effect between financial impact and the e-banks strategy assessments.

H3: There is a significant positive effect between internal process and the e-banks strategy assessments.

H4: There is a significant positive effect between customization and the e-banks strategy assessments.

H5: There is a significant positive effect between customers interaction and the e-banks strategy assessment.

\section{Literature Review}

Existing work in this area of research shows that e-banging strategy is the major potential sources of uncertainty faced by the strategic department; and also indicates a growing performance (Robin, Coulter, \& Keith, 2001).

\section{Strategy Assessment}

The idea behind strategy is coincident with the following definition "the search of an action plan to create and develop a competitive advantage". Turban et al. (2008) identified strategy as a long term plan. An organization strategy is abroad-based formula for how a business is going to accomplish its mission, what its goals are, and what plans and policies it will need to accomplish these goals. While the organization developed their strategy there's a specific activity should to be implemented these activates are the following: business opportunities, cost—benefit analysis, risk analysis, assessment, and management (K. Laudon \& J. Laudon, 2004). The strategy assessment is very important and helps the leadership to think where they want go and how to get there, strategy provides direction and context for business, and leads to the framework for aligning vision with missions, and helps to define goals (Stouse, 2002). 


\section{The Objectives of Strategy Assessment}

Strategic assessment has several objectives. The most important ones are:

- Measure the extent to which the EC strategy and ensuring projects are delivering what they are supposed to deliver;

- Determine if EC strategy and projects are still viable in the current environment;

- Reassess the initial strategy in order to learn from mistake;

- Identify failing projects as soon as possible and determine why they failed (K. Laudon \& J. Laudon, 2004; Patrick, 2005). Each company measures success of failure by a different set of standards, some companies may find that their goals unrealistic. However the strategy assessment helps to answer many of questions, and enable the organization to compete better in order to create unique products, services, relationships and operational efficiencies. However, typical performance metrics might include the following.

\section{Balanced Scorecard SWOT}

BSC SWOT, or the Balanced Scorecard SWOT analysis, was first introduced the BSC SWOT is a simple concept that combines the two powerful tools BSC and SWOT analysis when identifying factors that drives or hinders strategy. The four perspectives in BSC are combined with the four dimensions of SWOT in a matrix where findings may be inserted (Robson, 1997). Examples: To identify financial (first perspective of the BSC) strengths (the first dimension of SWOT analysis). Or to identify internal process (third perspective of the BSC) weaknesses (the second dimension of SWOT analysis). The full matrix is in Table 1:

Table 1

SWOT Analysis

\begin{tabular}{|c|c|c|c|c|}
\hline Metrics & Strengths & Weaknesses & Opportunities & Threats \\
\hline Financial & financial strengths & $\begin{array}{l}\text { financial } \\
\text { weaknesses }\end{array}$ & financial opportunities & financial threats \\
\hline Customer & customer strengths & $\begin{array}{l}\text { customer } \\
\text { weaknesses }\end{array}$ & customer opportunities & customer threats \\
\hline Internal processes & internal strengths & internal weaknesses & internal opportunities & internal threats \\
\hline People & people strengths & people weaknesses & people opportunities & people's threats \\
\hline
\end{tabular}

Note. Source: Robson, 1997.

The traditional SWOT analysis would look at external factors when looking at opportunities and threats. However, the BSC SWOT would consider these attributes from both an external and internal perspective. Each field in the matrix may be looked upon as a question. For instance: "What are my internal strengths" or "What opportunities do I have with my people”. The BSC SWOT concept works best if a full understanding of BSC and SWOT analysis exists in order to create the right outcome (Orton et al., 2006).

\section{Balanced Scorecard (BSC)}

Is a measurement system that enables organization to clarify and translate their vision strategy into action? BSC measurements provide feedback around both internal business process and external outcomes in order to continuously improve strategy performance and result. This method was devised by Kaplan and Norton (1996). It consists of four dimensions: customers, financial, internal business processes, innovation, and learning. The balanced scorecard is encouraged to measuring organization performance in number of areas (Skyrme, 2002; Skyrme \& Amidon, 1998). Some of these areas are the following. 


\section{Financial}

Caudle (2008) argued that the heart of BSC is the financial metrics; this prospective asks how the organization should appear to shareholders so that company can succeed financially. This perspective indicates that business is improving the bottom line, measuring item such as cash flow, return on investment, financial result, return on capital employed, return on equity, and economic value added. It defines the value proposition that the organization will apply to satisfy customers and thus generate more sales to the most desired customers (Strouse, 2002).

\section{Internal Business Processes}

This perspective asks what business process the organization should excel at to satisfy shareholder and customer (Pearlson \& Saunders, 2009). This perspective measures the internal business processes from the following: number of activities, opportunity success rate, accident ratios and environment compatibility, and overall equipment effectiveness (Pearlson \& Saunders, 2009).

\section{Learning and Growth}

This prospective asks how the organization would sustain its ability to change and improve to achieve the organization vision. The learning and growth perspective identifies the organization infrastructure needed to support the other objectives (Caudle, 2008). The prospective measures the following: investment rate, internal promotions, and employee turnover (Strouse, 2002).

\section{Customer Interaction}

This prospective asks how an organization should appear to customers to achieve the organizations vision. Customer's objectives identify customers and market segments where the business would compete and what performance would be expected for these targeted segments. The scorecard focuses on customer concerns primarily in four categories: time, quality, performances, service, and cost (Caudle, 2008). Kaplan and Norton (1996) noted that this method helped companies to move from being financially driven to mission driven. In other words, it becomes a key part of the wider management system of planning. Plant (2000) suggested seven areas for assessment of an e-commerce strategy: financial, impact, competitive, brand, service, market, technology, and internal site metric. Similarly, Zhu, and Kraemer (2002) suggested four metrics areas information, transaction, interaction, customization, and supplier connection. Finally Jaworski (2004) proposed five categories of financial and non-financial metrics. The BSC approach examines performance related to a lot of metrics, the BSC requires substantial amounts of data, it is necessary to establish organizational data warehouse of its perspectives, like human resources, customers, processes, and financial data that can be used in decision support (Daft \& Noe, 2004).

\section{Balanced Scorecard Benefits}

- Achieve increased focus strategy, execution and results;

- Align organization strategy performance by measuring what drives success;

- Focus on the drivers of future performance;

- Make better, information decisions using customer and employee’s information and perceptions;

- Improve communication of the organization vision and strategy using data;

- Prioritize projects and initiatives based on metrics (Norrie \& Slater, 2004). 


\section{Research Design}

The term research design refers to the overall strategy of the research. Thus, the research design should advise us on how the sample will be drawn. Research design is concerned with making our problems accessible by directing our research in a way that generates precise answers to precise question. There are two approaches that the research methodology can be derived from these two approaches can be classified into two main categories quantitative methodology, and qualitative methodology (Saskia, 2004). Consider the benefits and the drawbacks of the two methodologies. In addition to the study limitations, which are discussed below .The researcher adopted the quantitative approach due to the following reasons:

- Resource Limitation time, and cost of the study;

- The issues of validity and, reliability are often seriously questioned because of the nature of the data;

- The need to satisfy the research objectives in terms of testing hypotheses.

\section{Data Collection Methods}

The data and information will be gathered from two resources:

Primary resources:

Individuals focus groups, and a panel of respondents set up by the researcher whose opinions may be sought on specific issues from time to time are examples of primary data sources (Anastasi, 1982). Data can also be culled from administrating questionnaire. Questionnaires are an efficient data collection mechanism when the researcher knows exactly what is required and how to measure the variable of interest (Malhotra \& Briks, 2000). In this study, the questionnaires send to respondents in the senior level, top managers, and strategic management.

Secondary resources: Data can also be obtained from secondary sources, for example, company records or archives, industry analysis offered the media Web site, the internet, and so on (Sekaran, 1992). Using the scientific (Books, articles, etc.) concerned with the study.

\section{Initial Design and Development of the Survey Instrument}

Many criteria should be considered when designing a questionnaire survey (Sekaran, 1992). On the choice of wording, questionnaire design, and layout were adopted. Items in questionnaire were designed to being simple, clear, short, technical, accurate, bias free, and at an appropriate reading level (Malhotra \& Briks, 2000; Saskia, 2004). The authors were taken into account when designing the questionnaire, such as started with a brief description on how to answer the questionnaire. An initial draft of questionnaire was developed based on an extensive literature review, and existing measures.

\section{Decisions Related to Population and Sample Selections}

The banks market is huge and has been growing rapidly in recent years. Banks can use all of the e-services. However, many large banks receive additional e-services, the banks are seen as an appropriate business environment that is particularly suitable to test for the research model and the determinations of the BSC effects in e-banking strategy assessment, in Jordan, 16 banks, Arab banks controlling the local market and, account for more than $40-50 \%$ of the country's total production. Sekaran (1992) defined research population as any exactly defined set of people, or collection of items, that was under investigation. In the light of this definition, the research population, and the actual sample are identified as that the four banks dominate the local market and account for more than $75 \%$ of the country's total production. These are: Arab bank, the Housing bank for trading finance, Jordan bank, and Standard chartered bank. 
A questionnaire was send to respondent's strategic management. A stratified random sampling method will be used, as it is the most convenient, and the most applicable in the Jordan context. The unit of the analysis in this study is a strategic mangers working in Jordan banks. 200 questionnaires were sent to 200 populations which were 183 returned. Eleven questionnaires were ignored because it had missed. The overall response rate for this study is $90 \%$. The response rate actually used is $86 \%$. This is regarded as relatively high, since the respondents are strategic management supposed to be too busy to answer questionnaires. However, it is found that sample is sufficient to represent the regression analysis conducted.

\section{Operationalisation and Measurement Strategy of the Model Variables}

The measures of model variables in this were analyses by using statistical procedures starting with internal consistency test, establishing constructs reliability, statistical procedures are common among many researchers, such as Malhotra and Briks (2000).

(1) Internal consistency to assess the reliability of the scale by using Cronbach's alpha;

(2) Developing a structural model based on the composite measures to linking the hypothesized model's constructs;

(3) Multiple regression analysis to investigate the hypotheses.

\section{Internal Reliability}

The internal consistency measures (Cronbach's alpha) are obtained in order to assess the reliability of the measurement instruments. The following table shows the Cronbach's alpha value for each scale. It is clear that Cronbach's alpha, acceptable statistically and managerially because $(\alpha)$ values are greater than accepted $0.60 \%$.

Table 2

Cronbach's alpha

\begin{tabular}{lll}
\hline No. & Variables & Cronbach's alpha $(\alpha)$ \\
\hline 1 & Financial impact & 0.764 \\
2 & Internal process & 0.764 \\
3 & Customization & 0.644 \\
4 & Customers interaction & 0.832 \\
5 & Strategy assessment & 0.777 \\
\hline
\end{tabular}

\section{Descriptive Statistics}

Descriptive statistics such as means frequencies, and standard deviation, were used to identify the major characteristics of respondents in term of their gender, age, educational level, and working experience.

\section{Result}

All analyses were conducted with SPSS-PC. Frequency and percentage were used to describe the samples of the study and multiple regression analysis was conducted to test the research hypotheses.

- Measuring the effect between the independent variable and dependent variable simple regression;

- Most of the respondents agree that they have good and close relationship between BSC and strategy assessment with Mean $=3,77 ; \mathrm{SD}=0.97$. The result of the regression analysis shows that there is a significant positive relationship between the independent variables and strategy assessment ( $p<0.001)$. With $43.4 \%$ of variance in level which explained by the relationship of the sum of independent variable, which is supported by the hypothesis 1 . 


\section{The Effect Between Financial Impact and Strategy Assessment}

The results in Table 4 which relate to correlation between the independent variable (financial impact) and the dependent variable (strategy assessment). A positive and significant effect can be found at function level ( $\alpha$ $\leq 0.01)$ which supports hypothesis $(\mathrm{H} 2)$, where $(r=0.523)$. Based on the results in Table 3 which represent simple regression analysis, simple regression was used to test above hypothesis, and it was found that calculated $t(7.732)$ is significant at ( $\mathrm{p}<0.001)$ level, which means that there is a relationship between financial impact and the strategy assessment variance equal $47 \%$. The hypothesis 2 is supported.

Table 3

Descriptive Statistics

\begin{tabular}{lll}
\hline Demographic object & The valid items & Percent (\%) \\
\hline \multirow{2}{*}{ Gender } & Male & 72.7 \\
& Female & 27.3 \\
\hline \multirow{2}{*}{ Employee age } & $20-29$ & 46.0 \\
& $30-39$ & 31.38 \\
& $40-50$ & 14.17 \\
Education level & Above 50 & 8.45 \\
& College degree & 3.5 \\
& Bachelor degree & 88.4 \\
& Postgraduate degree & 8.1 \\
\hline \multirow{2}{*}{ Working experience } & Less than 6 & 9.0 \\
& From 1-2 years & 25.0 \\
& 5-10 years & 30.37 \\
\hline
\end{tabular}

Table 4

The Effect Between Financial Impact and Strategy Assessment

\begin{tabular}{lll}
\hline Variables & Beta & Sig. \\
\hline Financial impact and strategy assessment & 0.523 & 0.000 \\
\hline
\end{tabular}

\section{The Effect Between Internal Process and Strategy Assessment}

Based on the results in Table 5 which relate to correlation relationship between the independent variable (internal process) and the dependent variable strategy assessments. A positive and significant effect can be found at function level $(\alpha \leq 0.01)$ which supports hypothesis H3. Based on the results in Table 5, which represent simple regression analysis, simple regression was used to test above hypothesis, and it was found that calculated $t(9.906)$ is significant at (0.01) level, which means that there is a relationship. Significant effect can be seen at function level $(\alpha \leq 0.01)$ to the independent variable (internal process) in the dependent variable (strategy assessment). The variance is (0.447). The hypothesis 3 is supported.

Table 5

The Effect Between Internal Process and Strategy Assessment

\begin{tabular}{lll}
\hline Variables & Beta & Sig. \\
\hline Internal process and strategy assessment & 0.463 & 0.000 \\
\hline
\end{tabular}




\section{The Effect Between Customization and Strategy Assessment}

Based on the results in Table 6 which relate to correlation relationship between the independent variable (customization), and the dependent variable (strategy assessment). A positive and significant effect can be found at function level $(\alpha \leq 0.01)$, which supports hypothesis H4. Table 6 Simple regression was used to test above hypothesis and, it was found that calculated $t(7.414)$, is significant at (0.01) level, significant effect can be seen at function level $(\alpha \leq 0.01)$. The hypothesis 4 is supported partially.

Table 6

The Effect Between Customization and Strategy Assessment

\begin{tabular}{lll}
\hline Variables & Beta & Sig. \\
\hline Customization and strategy assessment & 0.219 & 0.000 \\
\hline
\end{tabular}

\section{The Effect Between Customers Interaction and Strategy Assessment}

Based on the results in Table 7 which relate to correlation relationship between the independent variable (customer Interaction), and the dependent variable (strategy assessment). A positive and significant effect can be found at function level ( $\alpha \leq 0.01$ ), which supports hypothesis H5. Table 7 simple regression was used to test above hypothesis and, it was found that calculated $t(10.515)$, is significant at (0.01) level, significant effect can be seen at function level $(\alpha \leq 0.01)$. The variance is $49 \%$. The hypothesis 5 is supported.

Table 7

The Effect Between Customers Interaction and Strategy Assessment

\begin{tabular}{lll}
\hline Variables & Beta & Sig. \\
\hline Customers interaction and strategy assessment & 0.516 & 0.000 \\
\hline
\end{tabular}

\section{Conclusions}

The balance scorecard is one of these new tools that has and will help the managers to better create objectives, to better achieve their goals, lay out better strategy maps and to better evaluate the company's activity. This new tool is in reality a measuring tool that helps the managers to keep a closer eye on four important aspects of the company: the learning and growth perspective, the business process, the customer, and the financial perspective. The aim of this research was to identify the features and benefits of an effective-banks measurement in order to strategy assessments.

The overall results of the investigation have supported the research model presented in figure. The results collectively indicate that, there is a strongly to moderate relationships between finance impact, internal process, customization, and customer interaction and e-banging strategy assessment. However, the finding revealed that the apply of BSC in Jordan e-banks informational exists. The finance impact, internal process, and customer interaction were found to be the main aspects to achieve organization strategy. The study demonstrates that the BSC is clearly feasible and powerful in non-financial issues like customer interaction, which supports the value propositions of the e-banking informational area and assists strategic managers to aligned strategy performance by measuring what drives success, and prioritize e-strategy initiatives based on BSC metrics. Finally, the study showed that was a weak correlation between customization and strategy assessment. The result leads to recommend that the strategic managers should be a wear for customer needs and requirements, if banks wish to maintain their customer base in a competitive environment in which customers have easy access to information for banks services. 


\section{References}

Anastasi, A. (1982). Psychological testing (5th ed.). New York: Mac Gregor Publishing Company.

Caudle, S. (2008, October). The balanced scorecards: A strategic tool in implementing homeland security strategies, homeland security affairs, 4(3). Retrieved from http://www. HSAJ.Org

Daft, R. L., \& Noe, R. (2004). Organizational behavior: Western publishing of Thomson learning (pp.585-612). United States of America.

Jaworski, S. (2004). How key performance indication E-commerce strategy. Retrieved June 2012, from http://www.businessknowhow.com

Kaplan, R., \& Norton, D. P. (1996, January-February). The balance scorecard measures that drive performance. Harvard Business review.

Kraemer, K. (2006). Global E-commerce: Impacts of national environments and policy. M.A.: Cambridge University Press.

Laudon, K., \& Laudon, J. (2004). Management information system (8th ed.). Pearson Prentice Hall.

Maiga, A., \& Jacobe, F. (2003). Balanced scorecard, activity-based costing and company performance: An empirical analysis. Journal of Management, 15(3).

Malhotra, K., \& Briks, D. (2000). Marketing research: An applied approach (European Edition). England: Pearson Education Ltd..

Norrie, J., \& Slater, S. F. (2004, December). A balance scorecard approach to project management leadership. Project management Journal (pp. 48-52).

Patrick, O. (2005). Balanced scorecards: A road map for executing strategy. Retrieved December 2010, from http://www.axsellit.com

Pearlson, C., \& Saunders, S. (2009). Strategic management information systems (4th ed.). Johan Wiley \& sons Inc..

Plant, R. T. (2000). E-commerce: Formulation of strategy. Upper Saddle River: Prentice Hall.

Robin, A., Coulter, G. Z., \& Keith, S. (2001). Interpreting consumer perception. Journal of Advertising (pp. 1-21).

Robson, W. (1997). Strategic management and information system an integrated approach. Pearson Education, Prentice Hill.

Saskia, S. (2004). Electronic markets and activist networks: The weight of social logics in digital formations. Copyright 2004.

Sekaran, U. (1992). Research methods for business: A skill building approach (2th ed.) (pp. 285-301). U.S.A.: Alynow University Press.

Skyrme, D. (2002). Measuring intellectual capital, a plethora of methods. Retrieved from January 2011, from http://www.skyrme.com/insights/24kmeas.htm\#why

Skyrme, J., \& Amidon, M. (1998). New measures of success. The Journal of Business Strategy, 19(1), 20-24.

Stephen, O., Karl, E., Umble, B. R., Jacqueline, M., \& Anne, J. M. (2006). Management academy for public health: Program design and critical success factors. J Public Health Management Practice, 12(5), 409-418.

Strouse, R. (2002). Strategic assessment for information providers. Director \& Lead Analyst Outsell, Inc.. Retrieved from http://www.outsellinc.com

Turban, E., King, D., Lee, J., \& Viehland, D. (2008). Electronic commerce: A managerial perspective (International Edition). New Jersey: Pearson Edition Inc..

Zhu, K., \& Kraemer, K. L. (2002). E-Commerce metrics for net-enhanced organizations: Assessing the value of e-commerce to firm performance in the manufacturing sector. Information Systems Research, 13(3), 275. 